\title{
Unveiling the bases of alkaline stability of an evolved versatile peroxidase
}

\author{
Verónica SÁEZ-JIMÉNEZ*, Sandra ACEBES††, Eva GARCIA-RUIZ§, Antonio ROMERO*, Victor \\ GUALLAR $\dagger \|$, Miguel ALCALDE\#, Francisco J. MEDRANO*, Angel T. MARTÍNEZ* and Francisco J. RUIZ- \\ DUEÑAS*1
}

\author{
*Centro de Investigaciones Biológicas, CSIC, Ramiro de Maeztu 9, E-28040 Madrid, Spain \\ $\dagger$ Joint BSC-CRG-IRB Research Program in Computational Biology, Barcelona Supercomputing Center, Jordi \\ Girona 29, E-08034 Barcelona, Spain \\ †Anaxomics Biotech, Balmes 89, E-08008 Barcelona, Spain \\ §Department of Chemical and Biomolecular Engineering, University of Illinois at Urbana-Champaign, 600 South \\ Mathews Avenue, Urbana, Illinois 61801, USA \\ ॥ICREA, Passeig Lluis Companys 23, E-08010 Barcelona, Spain \\ \#Institute of Catalysis and Petroleochemistry, CSIC, Marie Curie 2, Cantoblanco, E-28049 Madrid, Spain
}

Short title: Investigating the bases of stability in an evolved VP variant

Summary statement: We provide a structural basis for the improved alkaline stability of a versatile peroxidase obtained by directed evolution. New interactions promoted by three basic residues contribute to stabilize the heme and its environment helping to maintain the enzyme's structural integrity.

Key words: pH stability, versatile peroxidase, directed evolution, structure-function relationships

A variant of high biotechnological interest (called 2-1B) was obtained by directed evolution of the Pleurotus eryngii VP expressed in Saccharomyces cerevisiae (García-Ruiz et al. Biochem. J. 441, 487, 2012). 2-1B shows seven mutations in the mature protein that resulted in improved functional expression, activity and thermostability, along with a remarkable stronger alkaline stability. The latter is highly demanded for biorefinery applications. Here we investigate the structural bases behind the enhanced alkaline stabilization of this evolved enzyme. In order to do this, several VP variants containing one or several of the mutations present in 2-1B were designed, and their alkaline stability and biochemical properties determined. In addition, the crystal structures of 2-1B and one of the intermediate variants (both expressed in Escherichia coli) were solved and carefully analyzed, and molecular dynamics simulations for both native VP and 2-1B were carried out. We concluded that the introduction of three basic residues in VP (Lys-37, Arg-39 and Arg-330) led to new interactions at the heme-helix B (where the distal histidine is located) interface, and formation of two-three new salt bridges that avoided the hexacoordination of the heme iron. These new structural determinants stabilized the heme and its environment, helping to maintain the structural enzyme integrity (with pentacoordinated heme iron) under alkaline conditions. Moreover, the reinforcement of the solvent-exposed area around Gln-305 in the proximal side, prompted by the Q202L mutation, further enhanced the stability.

Abbreviations: ABTS, 2, 2-azinobis-(3-ethylbenzothiazoline-6-sulfonic acid); CDS, coding DNA sequence; CT, charge transfer (bands in electronic absorption spectra); DMP, 2,6-dimethoxyphenol; DTT, dithiothreitol; EDTA, ethylenediaminetetraacetic acid; GP, generic peroxidase; IPTG, isopropyl- $\beta$-D-thiogalactopyranoside; LiP, lignin peroxidase; MnP, manganese peroxidase; RB5, Reactive Black 5; VA, veratryl alcohol; VP, versatile peroxidase.

${ }^{1}$ To whom correspondence should be addressed (email fjruiz@cib.csic.es).

The coordinates and structure factors for the 2-1B and EHG variants of the Pleurotus eryngii VP have been deposited in the PDB under codes $5 \mathrm{fnb}$ and $5 \mathrm{fne}$, respectively. 


\section{INTRODUCTION}

Lignin is the main reservoir of aromatic compounds in living organisms and a valuable feedstock for the sustainable production of chemicals and materials [1;2]. Due to its aromatic and heterogeneous nature, lignin is highly resistant to chemical and biological degradation [3]. Whiterot fungi produce ligninolytic peroxidases involved in lignin degradation, and they are the only organisms in nature being able to extensively mineralize lignin [4;5]. Ligninolytic peroxidases include three families: lignin peroxidases (LiP, E.C. 1.11.1.14), which oxidize high redox potential substrates through an exposed tryptophan radical formed by electron transfer to the heme [6]; manganese peroxidases (MnP, E.C. 1.11.1.13), which oxidize $\mathrm{Mn}^{2+}$ to $\mathrm{Mn}^{3+}$ at a specific $\mathrm{Mn}$ binding site near one of the heme propionates [7;8]; and versatile peroxidases (VP, E.C. 1.11.1.16), which combine the catalytic properties of LiPs and MnPs (due to the simultaneous presence of the exposed tryptophan and the Mn-binding site, mentioned above) at the same time that they oxidize the typical substrates of generic peroxidases (GPs, E.C. 1.11.1.7) at the main heme access channel $[9 ; 10]$.

The above enzymes are naturally designed to overcome the recalcitrant nature of lignin taking advantage from their high redox potential, unspecific oxidation mechanism and other catalytic properties. Their use in industrial processes that require the oxidation of lignin and other phenolic and non-phenolic aromatic compounds and dyes is, therefore, very promising [11]. In this way, ligninolytic peroxidases could be used in the deconstruction of the lignocellulosic biomass and production of biofuels, materials and chemicals in lignocellulose biorefineries; in bioremediation processes for the treatment of recalcitrant dye wastes; or in bleaching applications in paper pulp manufacture $[2 ; 12 ; 13]$. However, there are some drawbacks that prevent the industrial application of these enzymes as they are produced in nature. Among them, it is possible to mention their relative low stability towards some conditions of $\mathrm{pH}$, temperature or hydrogen peroxide concentration, in which industrial processes are often carried out (including the alkaline conditions often used in lignocellulose processing) [2].

2-1B is an enzyme variant obtained by directed evolution of the VP from Pleurotus eryngii in Saccharomyces cerevisiae [14]. During the evolutionary process, seven mutations were introduced in the sequence of mature VP. As a consequence, 2-1B showed enhanced expression levels, increased thermo and alkaline stability, and improved oxidation of some substrates. In the present work, five VP variants containing one or several of the mutations present in 2-1B were designed, and their biochemical properties carefully evaluated, at the same time that the crystal structures of two of the most relevant variants were solved and used in molecular simulations. The final objective was to understand how the substitutions introduced by directed molecular evolution modulate the alkaline stability and catalytic properties of the enzyme, with the aim of using this information in future peroxidase engineering work.

\section{MATERIALS AND METHODS}

\section{Chemicals}

Isopropyl- $\beta$-D-thiogalactopyranoside (IPTG), dithiothreitol (DTT), ethylenediaminetetraacetic acid (EDTA), hemin, oxidized glutathione, veratryl alcohol (VA), manganese (II) sulphate, Reactive Black 5 (RB5), 2,6-dimethoxyphenol (DMP), sodium tartrate and other chemicals were purchased from Sigma-Aldrich; urea and hydrogen peroxide were from Merck; and 2, 2-azinobis-(3ethylbenzothiazoline-6-sulfonic acid) (ABTS) from Roche.

\section{Directed mutagenesis}

All VP variants but 2-1B (see below) were produced using the QuikChange ${ }^{\mathrm{TM}}$ Site-Directed Mutagenesis kit (Stratagene). Each mutation was introduced by PCR using the expression plasmid pFLAG1 (International Biotechnologies Inc.) containing the coding DNA sequence (CDS) of $P$. eryngii VPL (allelic variant VPL2; GenBank ${ }^{\mathrm{TM}}$ AF007222), named pFLAG1-VPL2, or the same plasmid containing already mutated CDSs as templates and two primers, a direct and a reverse 
primer designed complementary to opposite strands of the same DNA region containing the desired mutation.

The mutagenic primers E37K, $\mathrm{H} 39 \mathrm{R}_{\mathrm{p}}$ and $\mathrm{G} 330 \mathrm{R}_{\mathrm{p}}$ (Supplementary Table S1) were used to obtain the corresponding single variants. The double variant E37K/H39R was obtained using the plasmid pFLAG1-VPL2 as template and the primers E37K/H39R $\mathrm{R}_{\mathrm{p}}$ containing both $\mathrm{E} 37 \mathrm{~K}$ and $\mathrm{H} 39 \mathrm{R}$ mutations. The double variant E37K/G330R (hereinafter EG) was obtained using the plasmid pFLAG1-VPL2 harbouring the G330R mutation as template and the primers E37K . Similarly, the triple variant E37K/H39R/G330R (hereinafter EHG) was achieved using the plasmid pFLAG1VPL2 containing the E37K and H39R mutations as template and the primers G330R $\mathrm{R}_{\mathrm{p}}$. In the same way, the multiple variants E37K/H39R/Q202L/G330R (hereinafter EHGQ) and $\mathrm{E} 37 \mathrm{~K} / \mathrm{H} 39 \mathrm{R} / \mathrm{T} 184 \mathrm{M} / \mathrm{G} 330 \mathrm{R}$ (hereinafter EHGT) were obtained using the template pFLAG1-VPL2$\mathrm{E} 37 \mathrm{~K} / \mathrm{H} 39 \mathrm{R} / \mathrm{G} 330 \mathrm{R}$ with $\mathrm{Q} 202 \mathrm{~L}_{\mathrm{p}}$ or $\mathrm{T} 184 \mathrm{M}_{\mathrm{p}}$ as primers, respectively.

PCR reactions were carried out in an Eppendorf Mastercycler Pro S using $10 \mathrm{ng}$ of template DNA, $250 \mu \mathrm{M}$ each dNTP, $125 \mathrm{ng}$ of both direct and reverse primers, 2.5 units of Pfu Turbo AD polymerase (Stratagene) and the manufacture's reaction buffer. Reaction conditions were as follows: (i) a "hot start" of $95^{\circ} \mathrm{C}$ for $1 \mathrm{~min}$; (ii) 18 cycles at $95^{\circ} \mathrm{C}$ for $50 \mathrm{~s}, 55^{\circ} \mathrm{C}$ for $50 \mathrm{~s}$ and $68^{\circ} \mathrm{C}$ for $10 \mathrm{~min}$; and (iii) a final cycle at $68^{\circ} \mathrm{C}$ for $10 \mathrm{~min}$. Clones harbouring mutations were transformed into Escherichia coli DH5a. One positive clone of each variant was selected, sequenced (PerkinElmer ABI PRISM 377) and checked to confirm that the desired mutations had been properly introduced.

\section{Heterologous expression}

Wild-type recombinant (hereinafter native) VP and its directed variants were expressed in E. coli W3110 after transformation with the corresponding plasmids. The gene encoding the 2-1B variant was obtained by digesting the plasmid used for $S$. cerevisiae expression [14], cloned into pFLAG1 (resulting in the pFLAG-VPL2-2-1B construction) and transformed into E. coli W3110 for expression.

Cells were grown in Terrific Broth [15] at $37^{\circ} \mathrm{C}$ until $\mathrm{OD}_{500} \sim 1(\sim 3 \mathrm{~h})$. Then protein expression was induced with $1 \mathrm{mM}$ IPTG and cells were grown for a further $4 \mathrm{~h}$. The apoenzyme was produced as inclusion bodies and was recovered in a $50 \mathrm{mM}$ Tris- $\mathrm{HCl}(\mathrm{pH} 8.0)$ solution containing $8 \mathrm{M}$ urea, $1 \mathrm{mM}$ EDTA and $1 \mathrm{mM}$ DTT. The subsequent in vitro folding of the solubilised apoenzyme was carried out in a solution of $0.16 \mathrm{M}$ urea, $20 \mu \mathrm{M}$ hemin, $5 \mathrm{mM} \mathrm{CaCl} 2,0.1 \mathrm{mM}$ DTT, $0.5 \mathrm{mM}$ oxidized glutathione and $0.1 \mathrm{mg} / \mathrm{ml}$ protein concentration in $20 \mathrm{mM}$ Tris- $\mathrm{HCl}$ buffer, at $\mathrm{pH} 9.5$, at room temperature overnight. The refolded enzyme was purified by Resource-Q chromatography using a $0-0.3 \mathrm{M} \mathrm{NaCl}$ gradient $(2 \mathrm{ml} / \mathrm{min}, 20 \mathrm{~min})$ in $10 \mathrm{mM}$ sodium tartrate $(\mathrm{pH} 5.5)$ containing 1 $\mathrm{mM} \mathrm{CaCl}_{2}$. Finally, the purified enzyme was dialyzed against $10 \mathrm{mM}$ sodium tartrate $(\mathrm{pH} \mathrm{5)}$. The proteins showed Reinheitszahl values $\left(R_{z}, \mathrm{~A}_{407} / \mathrm{A}_{280}\right) \sim 4$ confirming their high purity. Their UVvisible spectra in the $300-700 \mathrm{~nm}$ range confirmed that they were correctly folded [16]. Enzyme concentrations were determined from the Soret absorbance $\left(\varepsilon_{407}=150 \mathrm{mM}^{-1} \mathrm{~cm}^{-1}\right)$ [17].

\section{pH stability studies}

Native VP and its directed variants $(1 \mu \mathrm{M})$ were incubated at different $\mathrm{pH}$ values (from 2 to 9) in $0.1 \mathrm{M}$ Britton-Robinson (B\&R) buffer [18] at $4^{\circ} \mathrm{C}$ for $120 \mathrm{~h}$. At different times $(1 \mathrm{~min}, 1 \mathrm{~h}, 4 \mathrm{~h}, 24$ $\mathrm{h}$ and $120 \mathrm{~h}$ ), aliquots were taken and their residual activity was evaluated by measuring the oxidation of ABTS $(2 \mathrm{mM})$ using $0.1 \mathrm{mM} \mathrm{H}_{2} \mathrm{O}_{2}$ and $0.01 \mu \mathrm{M}$ of enzyme in $0.1 \mathrm{M}$ sodium tartrate (pH 3.5). The activity obtained from samples incubated for 1 min at $\mathrm{pH} 5$ was taken as reference (maximum activity) to calculate the percentage of residual activity. Native VP and those variants showing improved alkaline stability (2-1B, EHG and EHGQ) $(4 \mu \mathrm{M}$ and $8 \mu \mathrm{M})$ were incubated at $\mathrm{pH} 5$ or $\mathrm{pH} 8$ in $0.1 \mathrm{M} \mathrm{B} \& \mathrm{R}$ buffer for $120 \mathrm{~h}$ at $4^{\circ} \mathrm{C}$, and their electronic absorption spectra (in the 300-800 nm range) were recorded using an Agilent 8453 diode array UV/visible spectrophotometer. 


\section{Kinetic constants}

Oxidation of $\mathrm{Mn}^{2+}\left(\mathrm{Mn}^{3+}\right.$-tartrate complex $\left.\varepsilon_{238} 6500 \mathrm{M}^{-1} \mathrm{~cm}^{-1}\right)$ was estimated at $\mathrm{pH} 5$; that of VA (veratraldehyde $\varepsilon_{310} 9300 \mathrm{M}^{-1} \mathrm{~cm}^{-1}$ ) at $\mathrm{pH} \mathrm{3}$; and those of RB5 $\left(\varepsilon_{598} 30000 \mathrm{M}^{-1} \mathrm{~cm}^{-1}\right)$, ABTS (cation radical $\varepsilon_{436} 29300 \mathrm{M}^{-1} \mathrm{~cm}^{-1}$ ) and DMP (coerulignone dimeric product $\varepsilon_{469} 55000 \mathrm{M}^{-1} \mathrm{~cm}^{-1}$ ) at $\mathrm{pH}$ 3.5. All enzymatic activities were measured as initial velocities taking linear increments of absorbance due to the appearance of the reaction product (decreases in the case of RB5). Reactions were performed in $0.1 \mathrm{M}$ tartrate buffer, at $25^{\circ} \mathrm{C}$, in the presence of $0.1 \mathrm{mM} \mathrm{H}_{2} \mathrm{O}_{2}$ using a variable wavelength Shimadzu UV-1800 spectrophotometer.

Steady-state kinetic constants were calculated from the estimated oxidation of increasing substrate concentrations until enzyme saturation was observed. Values and standard errors for affinity constant (Michaelis constant, $K_{\mathrm{m}}$ ) and maximal enzyme turnover (catalytic constant, $k_{\text {cat }}$ ) were obtained fitting the experimental measurements to the Michaelis-Menten model using SigmaPlot 12.0 software. Fitting of these constants to the normalized equation $v=\left(k_{\text {cat }} / K_{\mathrm{m}}\right)[\mathrm{S}] /$ $\left(1+[\mathrm{S}] / K_{\mathrm{m}}\right)$, where [S] is the substrate concentration, yielded the catalytic efficiency values $\left(k_{\mathrm{cat}} / K_{\mathrm{m}}\right)$ with their corresponding standard errors.

\section{Crystallization, data collection and crystal structure determination}

Crystallization trials were carried out by the sitting drop vapor diffusion method, using 96-well MRC2 plates with $50 \mu 1$ reservoir solution and the commercially available screenings from Emerald (Wizard classic crystallization screens I, II and III) and Jena Biosciences (JBScreen Classic Kits 110). Drops consisted of $0.2 \mu$ of protein solution $(10 \mathrm{mg} / \mathrm{ml}$ in $10 \mathrm{mM}$ sodium tartrate buffer at $\mathrm{pH}$ 5.0) and $0.2 \mu \mathrm{l}$ of reservoir solution. Crystallization was carried out at $22^{\circ} \mathrm{C}$. Crystals of $2-1 \mathrm{~B}$ were obtained in $0.1 \mathrm{M}$ Tris- $\mathrm{HCl}(\mathrm{pH} 7.8), 5 \%$ PEG3350, $1.25 \mathrm{M}\left(\mathrm{NH}_{4}\right)_{2} \mathrm{SO}_{4}$ and $7.5 \%$ glycerol; and cryoprotected raising the amount of glycerol up to $30 \%$. Crystals of EHG were obtained in $0.1 \mathrm{M}$ Na-acetate $(\mathrm{pH} 4.5), 1.26 \mathrm{M}\left(\mathrm{NH}_{4}\right)_{2} \mathrm{SO}_{4}$ and $0.2 \mathrm{M} \mathrm{NaCl}$; and cryoprotected with $0.8 \mathrm{M} \mathrm{Li}_{2} \mathrm{SO}_{4}$.

Crystals were mounted in nylon loops and flash-frozen in liquid nitrogen in the mother liquor containing the cryoprotectant indicated above. All diffraction data were obtained at $100 \mathrm{~K}$. X-ray diffraction intensities were collected at the X06DA beam line at the Swiss Light Source (Villigen, Switzerland) using a wavelength of $1.0000 \AA$. Diffraction data were indexed, integrated, merged and scaled using the program XDS [19]. Data collection statistics are shown in supplementary Table S2.

The structures of the two VP variants were solved by molecular replacement using the crystal structure of $P$. eryngii VPL (PDB entry 3FMU) as the search model and the program PHASER implemented in the PHENIX package [20]. The final models were obtained by consecutive rounds of refinement, performed with the PHENIX package; followed by manual model building, performed with Coot [21] using $\sigma_{\mathrm{A}}$ weighted $2 \mathrm{Fo}-\mathrm{Fc}$ and $\mathrm{Fo}-\mathrm{Fc}$ electron density maps. Solvent molecules were introduced in the structure automatically in the refinement as implemented in the PHENIX package and visually inspected. A total of $5 \%$ of reflections was used to calculate the $\mathrm{R}_{\text {free }}$ value throughout the refinement process. The structures were validated using MolProbity [22;23]. Refinement and final model statistics are summarized in supplementary Table S2. The coordinates and structure factors have been deposited with the Protein Data Bank. All figures were produced with PyMOL (http://www.pymol.org/).

\section{Molecular dynamics}

Structural and dynamical differences between wild type VP and its 2-1B variant were studied by molecular dynamics (MD) simulations. Hydrogen addition, ligand optimization, completion of the two terminal residues and protonation state adjustment of ionizable residues (Glu, His and Asp) in both crystal structures were performed with the protein preparation wizard [24] at $\mathrm{pH} \mathrm{8.} \mathrm{Molecular}$ dynamics were then produced with the Desmond software and its Maestro interface from Scrodinger Inc. Enzymes were solvated in an orthorhombic box with at least $10 \AA$ from the protein surface, followed by $\mathrm{NaCl}$ addition for an ionic force of $0.15 \mathrm{M}$. The default relaxation protocol in Desmond was performed followed by a $20 \mathrm{~ns}$ trajectory production with the OPLS-2005 [25] force 
field at 300K. The NPT ensemble with Nose-Hoover thermostat [26] and a Martyna-Tobias-Klein barostat [27] were employed.

\section{RESULTS}

\section{pH stability of the different variants}

VP 2-1B (containing E37K/H39R/V160A/T184M/Q202L/D213A/G330R mutations) expressed in E. coli showed improved alkaline stability (Figure 1D) compared with native VP (Figure 1A). After 24 and $120 \mathrm{~h}$ of incubation at $\mathrm{pH} 8$, it retained $82 \%$ and $78 \%$ of residual activity, respectively, whereas native VP was fully inactivated. Moreover, after $1 \mathrm{~h}$ of incubation at $\mathrm{pH} 9$, native VP retained only $5 \%$ of the initial activity while $2-1 \mathrm{~B}$ maintained $36 \%$ of activity. The differences in stability between both enzymes at neutral and most acidic $\mathrm{pH}$ conditions (in the $\mathrm{pH} 3.5-7$ range) were minimal, and 2-1B was less stable at the lowest $\mathrm{pH}$ value $(\mathrm{pH} 3)$ assayed.

To analyze the effect of each of the individual mutations in 2-1B, and the effect of combining them, several single and multiple VP variants were designed (Table 1), expressed in E. coli and characterized. The H39R variant showed high instability at acidic and alkaline $\mathrm{pH}$ values compared with native VP (Figure S1A). Native VP maintained around $90 \%$ of the initial activity in the range of $\mathrm{pH} 4-7$ after $120 \mathrm{~h}$ of incubation, while $\mathrm{H} 39 \mathrm{R}$ only showed $41 \%, 68 \%$ and $21 \%$ activity at $\mathrm{pH} 4$, 5 and 6 respectively (and no activity at $\mathrm{pH}$ 7). The following VP variant analyzed, EG containing mutations E37K/G330R, exhibited similar $\mathrm{pH}$ stability than native VP and no improvement in the alkaline range was observed (Figure S1B).

Surprisingly, the EHG variant, which combined the mutations of the two variants previously analyzed (E37K/H39R/G330R), displayed an increase in the alkaline stability compared with native VP (Figure 1B). This triple variant maintained 55\% of the initial activity after $120 \mathrm{~h}$ of incubation at $\mathrm{pH}$ 8, whereas native VP not only showed no activity under these conditions but it was inactivated after $24 \mathrm{~h}$ of incubation (Figure 1A). In a similar way, after $1 \mathrm{~h}$ of incubation at $\mathrm{pH} 9$, EHG exhibited a $46 \%$ of the initial activity, whereas native VP only retained $5 \%$. Moreover, this variant maintained a similar stability compared with native $\mathrm{VP}$ at acidic and neutral $\mathrm{pH}$ values. However, the values of $\mathrm{pH}$-stability observed for EHG were not as high as those obtained for 2-1B, which retained $78 \%$ of activity after $120 \mathrm{~h}$ of incubation at $\mathrm{pH} 8$.

The next VP variant analyzed was EHGQ (E37K/H39R/Q202L/G330R), which harboured the three mutations of EHG plus the Q202L mutation, also found in 2-1B. EHGQ showed 67\% of residual activity after $120 \mathrm{~h}$ of incubation at $\mathrm{pH} 8$ (Figure 1C), a value higher than that of EHG (55\% of activity). EHGQ also retained a low percentage of the initial activity (24\%) after $1 \mathrm{~h}$ incubation at $\mathrm{pH} 9$ compared with native $\mathrm{VP}$, which was completely inactivated. Therefore, it was determined that Q202L substitution also contributed to the enhancement of the pH stability in 2-1B. As previously described for $\mathrm{EHG}$, its stability at neutral and acidic $\mathrm{pH}$ was similar to that of the native VP.

The last variant tested, EHGT (E37K/H39R/T184M/G330R), harboured the three mutations introduced in EHG plus the T184M mutation, also found in 2-1B. After $120 \mathrm{~h}$ at $\mathrm{pH} \mathrm{8}$, EHGT displayed $30 \%$ of the initial activity (Figure S1C) compared with 55\% of activity retained by EHG. In consequence, we concluded that the T184M substitution did not contribute to the alkaline stability of 2-1B.

\section{pH effect on the UV-visible spectra}

The electronic absorption spectra of native VP and its variants were recorded after incubation at alkaline $\mathrm{pH} 8$, and at $\mathrm{pH} 5$ at which all of them are stable, to check the eventual modification of the heme interactions with its protein environment. As expected, all the spectra at $\mathrm{pH} 5$ exhibited a Soret maximum at $407 \mathrm{~nm}$, maxima at $505 \mathrm{~nm}$ and $637 \mathrm{~nm}$ corresponding to ligand-to-metal charge transfer bands (CT2 and CT1 respectively), and the $\beta$ band at $541 \mathrm{~nm}$ (Figure 2, black lines), which correspond to the typical spectrum of the ferric enzyme with high-spin pentacoordinated heme iron.

However, the spectrum of native VP after incubation at $\mathrm{pH} 8$ suffered important changes (Figure 2A, gray lines). The Soret maximum was red-shifted to $413 \mathrm{~nm}$ and showed less intensity, the CT 
bands at $505 \mathrm{~nm}$ and $637 \mathrm{~nm}$ disappeared and a new maximum rose at $538 \mathrm{~nm}$ ( $\beta$ band) together with a shoulder at $559 \mathrm{~nm}$ ( $\alpha$ band). In contrast, 2-1B preserved the spectrum mostly unaltered when incubated at $\mathrm{pH} 8$ (Figure 2D, gray lines), maintaining the Soret maximum at $407 \mathrm{~nm}$, as well as the CT1, CT2 and $\beta$ bands at 637, 505 and $541 \mathrm{~nm}$, respectively. In the same way, the EHG and EHGQ variants also preserved the ferric high-spin heme spectrum with all maxima unaffected (Figure 2B and 2C, gray lines, respectively).

\section{Catalytic properties}

Different substrates are oxidized at specific VP sites: i) high redox potential VA and RB5 are oxidized at the catalytic tryptophan; ii) low redox potential ABTS and DMP are oxidized both at the catalytic tryptophan (high efficiency site) and at the heme channel in direct contact with the heme edge (low efficiency site); and iii) $\mathrm{Mn}^{2+}$ is oxidized at the $\mathrm{Mn}^{2+}$-binding site, in direct contact with a heme propionate. The steady-state kinetic constants for the oxidation of the above five substrates by native VP and four variants were measured (Table 2).

In general, the oxidation of substrates in the catalytic tryptophan was not affected by the substitutions introduced in 2-1B, since the kinetic constants for the oxidation of VA, RB5, and ABTS and DMP (in the high efficiency site) were mostly unaltered in this and the other variants. The only exception was EHGT which exhibited a 3-fold higher catalytic efficiency $\left(559 \mathrm{~s}^{-1} \mathrm{mM}^{-1}\right)$ for DMP oxidation, compared with that of native VP $\left(186 \mathrm{~s}^{-1} \mathrm{mM}^{-1}\right)$, due to a decrease in the affinity constant $\left(K_{\mathrm{m}}\right)$.

$\mathrm{Mn}^{2+}$ oxidation was impaired in 2-1B and the rest of analyzed variants since their efficiency values were decreased around 60-fold, changing from $1640 \mathrm{~s}^{-1} \mathrm{mM}^{-1}$ in native VP to $25-30 \mathrm{~s}^{-1} \mathrm{mM}^{-1}$ in the variants. The worsening in the oxidation was mainly due to the increase of the $K_{\mathrm{m}}$ values.

Interestingly, the oxidation of ABTS and DMP at the low efficiency site was improved in 2-1B and EHGT. The efficiency for the oxidation of ABTS showed a 9-12-fold increase in both variants, mainly due to a reduction of the $K_{\mathrm{m}}$ values. In a similar way, the efficiency in the oxidation of DMP exhibited a 5-fold increase. In EHGT, this improvement was mainly due to the decrease in the $K_{\mathrm{m}}$. However, in 2-1B, a decrease of the $K_{\mathrm{m}}$ value combined with an increase of the $k_{\text {cat }}$ was observed.

In contrast to the results obtained for EHGT, EHG showed no improvement in ABTS and DMP oxidation. Since the only difference between these two variants is the T184M mutation present in EGHT, it was concluded that this substitution is involved in the improved oxidation of low redox potential substrates by EGHT (and probably by 2-1B).

\section{Analysis of crystal structures}

The crystal structures of 2-1B and EHG were obtained, analyzed and compared with that of native VP (PDB entry 2BOQ) to explain, from a structural point of view, both the enhanced alkaline stability and the modified catalytic properties of these variants. The simultaneous presence of H39R, E37K and G330R mutations was determinant for the higher alkaline stability found in 2-1B. Residues 37 and 39 are partially solvent-exposed, close to the heme (at 7.1 and $3.3 \AA$, respectively, in native VP structure) (Figure 3A) and close to the $\mathrm{Mn}^{2+}$-binding site (formed by Glu-36, Glu-40 and Asp-175). They belong to helix B, which is located directly above the heme and harbours the distal histidine (His-47) and the distal arginine (Arg-43) that are involved in catalysis. Moreover, the distal histidine is involved in the hexacoordination of the heme iron observed at alkaline $\mathrm{pH}$. The new Arg-39 in EHG and 2-1B (Figure 3C and D) showed a different orientation of its side chain relative to the position of His-39 in native VP (Figure 3B). The new orientation enabled the formation of a new $\mathrm{H}$-bond with the distal propionate of the heme, being this interaction absent in native VP. Instead, in VP, His-39 formed two H-bonds with Cys-34 and Pro-190, which were lost in the improved variants.

The E37K substitution changed an acidic residue for a basic one. The new lysine forms a salt bridge with Glu-40 in 2-1B (Figure 3D) and a double salt bridge with Glu-36 and Glu-83 in EHG (Figure 3C). In contrast, the side chain of Glu-37 in VP does not make this type of interactions (Figure 3B). On the other hand, Glu-37 is close $(<7 \AA)$ to several acidic residues (such as Glu-40 
and Glu-36 on helix B, Glu-83 on helix C, Glu-26 on helix A and Asp-30 and Asp-175 on two loops). Therefore, the introduction of the new Lys-37 in 2-1B and EHG variants contributed to reduce the putative destabilizing acid-acid interactions in the region where this mutation is located.

G330R was also involved in the $\mathrm{pH}$-stability improvement of 2-1B. This is the penultimate residue in the VP C-terminal tail, and its position could not be determined in the crystals of native VP and its mutated variants due to the high mobility of this area. For this reason, we could not verify in which way this mutation contributes to enhance the stability. Nonetheless, it is interesting to note that residue 330 is close to residues 37 and 39, all of them around the $\mathrm{Mn}^{2+}$-binding site.

Q202L, at the bottom of the molecule (Figure 4A), was the last mutation identified as stabilizing VP under alkaline conditions. The introduction of Leu-202 in 2-1B led to the disappearance of two H-bonds present in native VP, one with Ala-235 and other with Glu-304 (Figure 4B and $\mathbf{C}$ ). As a consequence, the position of the side chain of some surrounding residues changed in the 2-1B variant, especially that of Gln-305 forming three new interactions with Gln245, Cys-307 and Thr-310 in 2-1B. These interactions reinforced and joined two solvent-exposed regions of the protein: i) the helix I; and ii) the loop between the $3_{10}$ helix (from Leu-300 to Asp302) and the C-terminal tail. None of these interactions appeared in native VP.

Regarding the structural calcium ions, described as essential for $\mathrm{pH}$ stability, both of them appeared in the 2-1B and EHG structures coordinated in the same way as in the native VP.

Finally, the T184M mutation was analyzed in the 2-1B structure since it was involved in the enhanced oxidation of ABTS and DMP at the low efficiency site. Residue 184 is solvent exposed and located below the $\mathrm{Mn}^{2+}$-binding site. No significant differences were observed between native VP and 2-1B neither in the position of the surrounding residues nor in the interactions among them.

\section{Molecular dynamics}

Taking advantage of the solved crystal structures, the dynamics of native VP and 2-1B in solution were studied by MD simulations at $\mathrm{pH} 8$. Since alkaline inactivation has been related to the formation of a hexacoordinated iron complex with the distal histidine, we monitored the evolution of this distance aiming at possible correlations with the stability of the enzyme. Figure 5A shows the iron to His-47 distance along a $20 \mathrm{~ns}$ molecular dynamics for both enzymes. Although this distance is similar in both crystals, the addition of thermal fluctuations at room temperature reveals a different behavior, with a higher distance $(\sim 1 \AA$ difference on average) for the 2-1B variant. Such distance elongation is the result of a new hydrogen bond between Arg-43 and His-47 (Figure 5C), which is not formed in native VP because of the long distance between these two residues (Figure 5B and 5D). Overall, inspection of the simulated trajectory indicates a slight shift (along with a higher mobility) in the Arg-43 position, facilitating its interaction with His-47. This deviation towards the histidine is mainly due to the electrostatic repulsion produced by the introduction of three new positive residues in the propionate region (E37K, H39R, G330R). In addition, the H39R mutant, introduces a stronger interaction with Glu-40, weakening the contact of this glutamic acid with Arg-43. In native VP, Arg-43 interacts mostly with Glu-40, keeping it away from His-47 and allowing a closer distance of the distal histidine with the heme iron, facilitating the inactivation of the enzyme.

\section{DISCUSSION}

The 2-1B variant of $P$. eryngii VP contains seven mutations, introduced during the evolution process in $S$. cerevisiae, that conferred, among other properties, significantly improved alkaline stability and enhanced activity on some low redox potential substrates [14]. In the present work we identified some of the structural bases of the alkaline stabilization of this VP variant, by analyzing the stability at basic $\mathrm{pH}$ and catalytic properties of a series of (single and multiple) variants expressed in E. coli.

First, we confirmed that 2-1B expressed in E. coli retains the improved properties in terms of alkaline stability and activity at acid $\mathrm{pH}$ on low redox potential compounds observed when expressed in $S$. cerevisiae. However, it is possible to mention that, although 2-1B produced in $E$. 
coli showed a significantly increased alkaline stability (retaining $80 \%$ and $20 \%$ activity after $120 \mathrm{~h}$ at $\mathrm{pH} 8$ and $\mathrm{pH} 9$, respectively) compared with native VP (which was completely inactivated), this improvement was not as high as found when the variant was expressed in $S$. cerevisiae $(100 \%$ and $60 \%$ activity at $\mathrm{pH} 8$ and $\mathrm{pH} 9$, respectively) [14]. These differences are likely due to the lack of glycosylation of 2-1B expressed in E. coli, as reported for temperature stability of Phanerochaete chrysosporium ligninolytic peroxidases [28]. In general, glycosylation has been described to give robustness, thermostabilization and protection against enzyme inactivation [29;30] and, therefore, could reinforce the alkaline stabilizing effect of the mutations introduced in 2-1B.

\section{Explaining the alkaline stability}

During alkaline inactivation, ligninolytic peroxidases lose their structural calcium ions responsible for maintaining the architecture of the heme environment. This loss leads to a relaxation of the protein structure and hexacoordination of the heme involving the distal histidine [31]. These changes are reflected in the electronic absorption spectrum, which is indicative of the high or low spin states of the heme iron and its coordination state [32]. The P. eryngii native VP was inactivated in $24 \mathrm{~h}$ upon alkaline incubation $(\mathrm{pH} 8)$, showing the spectrum of a low-spin hexacoordinated heme iron. This is characterized by the red-shifted Soret band and the appearance of the $\alpha$ and $\beta$ bands. Similar changes have been reported for Bjerkandera adusta VP [33] and other ligninolytic peroxidases, such as LiP [31] and $\mathrm{MnP}$ [32] from P. chrysosporium. In contrast, the EHG variant showed improved alkaline stability and conserved the UV-visible spectrum (including the Soret maximum and the $\mathrm{CT} 1$ and $\mathrm{CT} 2$ bands) unchanged during incubation at $\mathrm{pH}$ 8. This spectrum is indicative of a peroxidase with a high-spin ferric state of the heme iron, which is completely functional [34;35]. From these data, it can be inferred that the three new basic residues present in EHG (Lys-37, Arg-39 and Arg-330) reinforced the heme environment enabling the maintenance of pentacoordinated heme iron at $\mathrm{pH} 8$.

The stability improvement achieved with the simultaneous introduction of these basic residues could be rationalized by comparative structural analysis and MD simulations of the EHG, 2-1B and native VP crystal structures. The new Arg-39 appeared hydrogen-bonded to the heme distal propionate in the molecular structure of the two variants. The connections of the heme with the apoprotein have been described as essential for stability [36;37] and engineering new connections with the heme has been proposed as an strategy to increase stability [38]. The heme in ligninolytic peroxidases is non-covalently bound and shows no polar interactions with the apoprotein, with the exception of those that the propionates make. So, the new connection made by Arg-39 seems to be important for the stability achieved, as it anchors the heme to the protein (helix B) and contributes to fix the relative position of His-47 with respect to the iron ion.

On the other hand, the new Lys-37 forms new salt bridges. These interactions have been positively correlated with stability in different families of proteins [39-42]. Those of Lys-37 with Glu-36 and Glu83 in EHG and with Glu-40 in 2-1B reinforced the structure of helix B, located directly above the heme and harbouring distal histidine (His-47) and arginine (Arg-43), which are essential in the reaction of the enzyme with $\mathrm{H}_{2} \mathrm{O}_{2}$ [43] and in the stabilization of the oxidized forms of the heme iron [44;45]. Moreover, as in the case of H39R mutation, fixing the helix B position reduces the possibilities of His-47 to approach the heme and generate the inactive form with hexacoordinated iron. Helix B also contains Asp-48, one of the residues coordinating the distal calcium, which is required for $\mathrm{pH}$ stability. In addition, a high number of acidic residues were observed around residue 37. At alkaline $\mathrm{pH} 8$, these residues would be deprotonated. In consequence, a high negative charge would characterize this region. The introduction of a basic residue (Lys-37) would reduce the negative charge avoiding detrimental interactions and reinforcing the structure of $\mathrm{VP}$ at alkaline $\mathrm{pH}$. At acidic $\mathrm{pH}$, however, the acidic residues will be protonated and no accumulation of negative charge would be produced, explaining the lack of acidic stability improvement of EHG and 2-1B.

The G330R mutation also contributed to the improved stability found in 2-1B and EHG. Although the role played by Arg-330 could not be studied in the crystal structures, it is likely that 
this residue located in the same area as residues 37 and 39 forms new interactions stabilizing the surrounding region containing a high number of acidic residues.

It was remarkable the fact that the stabilizing effect produced by Lys-37, Arg-39 and Arg-330 was only detected when they appeared together, since the H39R variant was unstable and the E37K/G330R variant showed a similar stability to that of the native VP. The sum of the new interactions formed by these residues results in the stabilization of VP but, individually, they make the protein instable due to the vulnerability of the region where they are (near the heme and the $\mathrm{Mn}^{2+}$-binding site), being a clear effect of positive epistasis unveiled by directed evolution [14]. According to the structural analysis described above, this effect is caused by the three basic residues simultaneously contributing to stabilize the relative position of the distal histidine. The MD simulations performed under alkaline conditions were quite enlightening in this regard. They revealed that the electrostatic repulsion, formed as a consequence of the introduction of Lys-37, Arg-39 and Arg-330, along with other interactions in which these and other surrounding residues are involved, is able to maintain the distal histidine for longer in a position far enough from the porphyrin to keep the heme iron in a pentacoordinate active state.

The EHGQ (E37K/H39R/G330R/Q202L) variant showed higher stability than EHG and almost achieved the alkaline stability found in 2-1B, so it was concluded that: i) the Q202L mutation also contributed to the enzyme stabilization; and ii) the four mutations introduced in EHGQ are responsible for the most part of the enhancement towards alkaline stability found in 2-1B. From the analysis of the crystal structure of 2-1B, it was observed that the Q202L substitution promoted the reorganization of Gln-305 and the formation of new interactions in the area which could explain the improvement observed due to this mutation. Although residue 202 is in the core of the protein, the residues affected by the new interactions are solvent exposed. The solvent exposed regions are very sensitive to $\mathrm{pH}$ changes, so the reinforcement of these areas could be determinant to strengthen the structure and avoid the alkaline inactivation at $\mathrm{pH}$ 8. Moreover, residue 202 would be an example of a residue located far from the heme and the rest of catalytic sites that is able to increase the stability of the enzyme.

\section{Explaining the modified catalytic properties}

Regarding the catalytic properties of $2-1 \mathrm{~B}$, it was found that this variant is more efficient than the native enzyme oxidizing low redox potential substrates, mainly due to an increased affinity (a decreased $K_{\mathrm{m}}$ ) in the low efficiency site. The same behaviour was previously reported for 2-1B expressed in S. cerevisiae [14]. With the data in hand, this fact was attributed to the presence of the T184M mutation. It is possible to speculate that the substitution introduced could help to a better substrate accommodation at the main heme access channel. However, the absence of structural differences in the environment of the residue at position 184 after comparative structural analysis of the native enzyme and $2-1 \mathrm{~B}$, has not allowed us to give a rational explanation to the effect produced by this mutation on the catalytic activity.

The simultaneous worsening in manganese oxidation is explained by the introduction of Lys-37 and Arg-39 [14]. These two residues could compromise the $\mathrm{Mn}^{2+}$ binding by forming salt bridges with Glu-36 and Glu-40 (two of the three residues involved in Mn-coordination together with Asp175) in EHG and 2-1B, respectively. Moreover, it is also probable that the new interaction established between the heme internal propionate and the apoprotein in 2-1B and EHG affects the $\mathrm{Mn}^{2+}$ binding and oxidation, considering that this propionate is involved in these two events [46]. Interestingly, the kinetic constants for $\mathrm{Mn}^{2+}$ oxidation in $2-1 \mathrm{~B}$ and the rest of variants were similar to that obtained for VP E36D and E40D variants [46], which suffered a shortening of the lateral chain of Glu-36 and Glu-40 (substitution by aspartic acid). These substitutions led to a worsening in the $\mathrm{Mn}^{2+}$ oxidation reflected in a high increase (25-fold) of the $K_{\mathrm{m}}$ and a consequent decrease in the efficiency. In the same way, 2-1B and derived variants showed $K_{\mathrm{m}}$ values 43 -54-fold higher. It is likely that salt bridges formed by Lys-37 in EHG and 2-1B were limiting the mobility of Glu-36 and Glu-40 leading to an impaired activity towards manganese in a similar way as happened with the E36D and E40D variants. Finally, substrate oxidation at the catalytic tryptophan was not 
impaired by the mutations introduced in 2-1B given that the oxidation of high redox compounds such as VA and RB5 by this variant was similar to that found in native VP. This is indicative of the maintenance of the high redox potential of the enzyme, determined by the position of the proximal histidine and by the strength of the interaction between this residue and the heme iron [47;48].

\section{Conclusions}

We were able to provide a structural-functional basis for the improved alkaline stability of the 2-1B variant by designing and characterizing several (individual and multiple) intermediate variants with the same mutations found in 2-1B. The E. coli expression system used not only facilitated variant generation by site-directed mutagenesis, but also enabled crystallization of the non-glycosylated forms of two of them. In this way, the introduction of three basic residues in VP (Lys-37, Arg-39 and Arg-330) resulted in new interactions at the heme environment that avoided the hexacoordination of the heme iron, which leads to enzyme destabilization at $\mathrm{pH} 8$. Moreover, the reinforcement of the solvent-exposed area around Gln-305, in the proximal side, further enhanced the stability. Interestingly, the biochemical characterization of the intermediate variants revealed discrete stability improvements, and the combination of most of them was required to stabilize VP. This stabilization could be obtained by random combination of mutations using directed molecular evolution, and would be impossible by a rational approach since the basis for the synergistic improvements observed could not be predicted "a priori".

\section{Author contributions}

V. Sáez-Jiménez performed most of the experimental biochemical work. S. Acebes and V. Guallar contributed to the molecular dinamycs analyses. F.J. Medrano and A. Romero crystallized VP variants. All authors participated in the interpretation and discussion of results. V. Sáez-Jiménez , A.T. Martínez and F.J. Ruiz-Dueñas contributed data integration and writing.

\section{Acknowledgments}

V.S.-J. and F.J.R.-D. thank the financial support of a FPI fellowship and a Ramón y Cajal contract of the Spanish Ministry of Economy and Competitiveness (MINECO), respectively.

\section{Funding}

This work was supported by HIPOP (BIO2011-26694), NOESIS (BIO2014-56388-R) and DEWRY (BIO2013-43407-R) projects of the Spanish Ministry of Economy and Competitiveness (MINECO), and by the PEROXICATS (KBBE-2010-4265397) and INDOX (KBBE-2013-7-613549) European projects.

\section{REFERENCES}

1 Ragauskas, A. J., Beckham, G. T., Biddy, M. J., Chandra, R., Chen, F., Davis, M. F., Davison, B. H., Dixon, R. A., Gilna, P., Keller, M., Langan, P., Naskar, A. K., Saddler, J. N., Tschaplinski, T., Tuskan, G. A. and Wyman, C. E. (2014) Lignin valorization: improving lignin processing in the biorefinery. Science, 344, 1246843

2 Martínez, A. T., Ruiz-Dueñas, F. J., Martínez, M. J., del Río, J. C. and Gutiérrez, A. (2009) Enzymatic delignification of plant cell wall: from nature to mill. Curr. Opin. Biotechnol., 20, 348-357

3 Ruiz-Dueñas, F. J. and Martínez, A. T. (2009) Microbial degradation of lignin: How a bulky recalcitrant polymer is efficiently recycled in nature and how we can take advantage of this. Microbial Biotechnol., 2, 164-177

4 Martínez, A. T., Speranza, M., Ruiz-Dueñas, F. J., Ferreira, P., Camarero, S., Guillén, F., Martínez, M. J., Gutiérrez, A. and del Río, J. C. (2005) Biodegradation of lignocellulosics: Microbiological, chemical and enzymatic aspects of fungal attack to lignin. Int. Microbiol., 8, 195-204

5 Floudas, D., Binder, M., Riley, R., Barry, K., Blanchette, R. A., Henrissat, B., Martínez, A. T., Otillar, R., Spatafora, J. W., Yadav, J. S., Aerts, A., Benoit, I., Boyd, A., Carlson, A., Copeland, A., Coutinho, P. M., de Vries, R. P., Ferreira, P., Findley, K., Foster, B., Gaskell, J., Glotzer, D., Górecki, P., Heitman, J., Hesse, C., Hori, C., Igarashi, K., Jurgens, J. A., Kallen, N., Kersten, P., Kohler, A., Kües, U., Kumar, T. K. A., Kuo, A., LaButti, K., Larrondo, L. F., Lindquist, E., Ling, A., Lombard, V., Lucas, S., Lundell, T., Martin, R., McLaughlin, D. J., Morgenstern, I., Morin, E., Murat, C., Nolan, M., Ohm, R. A., Patyshakuliyeva, A., Rokas, A., Ruiz-Dueñas, F. J., Sabat, G., Salamov, A., Samejima, M., Schmutz, J., Slot, J. C., St.John, F., Stenlid, J., Sun, H., Sun, S., Syed, K., Tsang, A., Wiebenga, A., 
Young, D., Pisabarro, A., Eastwood, D. C., Martin, F., Cullen, D., Grigoriev, I. V. and Hibbett, D. S. (2012) The Paleozoic origin of enzymatic lignin decomposition reconstructed from 31 fungal genomes. Science, 336, 1715-1719

6 Hammel, K. E. and Cullen, D. (2008) Role of fungal peroxidases in biological ligninolysis. Curr. Opin. Plant Biol., 11, 349-355

7 Gold, M. H., Youngs, H. L. and Gelpke, M. D. (2000) Manganese peroxidase. Met. lons Biol. Syst., 37, 559-586

8 Fernández-Fueyo, E., Acebes, S., Ruiz-Dueñas, F. J., Martínez, M. J., Romero, A., Medrano, F. J., Guallar, V. and Martínez, A. T. (2014) Structural implications of the C-terminal tail in the catalytic and stability properties of manganese peroxidases from ligninolytic fungi. Acta Crystallogr. D. Biol. Crystallogr., 70, 3253-3265

9 Ruiz-Dueñas, F. J., Morales, M., García, E., Miki, Y., Martínez, M. J. and Martínez, A. T. (2009) Substrate oxidation sites in versatile peroxidase and other basidiomycete peroxidases. J. Exp. Bot., 60, 441-452

10 Morales, M., Mate, M. J., Romero, A., Martínez, M. J., Martínez, A. T. and Ruiz-Dueñas, F. J. (2012) Two oxidation sites for low redox-potential substrates: A directed mutagenesis, kinetic and crystallographic study on Pleurotus eryngii versatile peroxidase. J. Biol. Chem., 287, 41053-41067

11 Martínez, A. T., Ruiz-Dueñas, F. J., Gutiérrez, A., del Río, J. C., Alcalde, M., Liers, C., Ullrich, R., Hofrichter, M., Scheibner, K., Kalum, L., Vind, J. and Lund, H. (2014) Search, engineering and applications of new oxidative biocatalysts. Biofuels Bioprod. Biorefining, 8, 819-835

12 Ragauskas, A. J., Williams, C. K., Davison, B. H., Britovsek, G., Cairney, J., Eckert, C. A., Frederick, W. J., Hallett, J. P., Leak, D. J., Liotta, C. L., Mielenz, J. R., Murphy, R., Templer, R. and Tschaplinski, T. (2006) The path forward for biofuels and biomaterials. Science, 311, 484-489

13 Husain, Q. (2010) Peroxidase mediated decolorization and remediation of wastewater containing industrial dyes: a review. Rev. Environ. Sci. Bio., 9, 117-140

14 García-Ruiz, E., González-Pérez, D., Ruiz-Dueñas, F. J., Martínez, A. T. and Alcalde, M. (2012) Directed evolution of a temperature-, peroxide- and alkaline $\mathrm{pH}$-tolerant versatile peroxidase. Biochem. J., 441, 487-498

15 Sambrook, J. and Russell, D. W. (2001) Molecular cloning, CSHL Press, Cold Spring Harbor, New York

16 Pérez-Boada, M., Doyle, W. A., Ruiz-Dueñas, F. J., Martínez, M. J., Martínez, A. T. and Smith, A. T. (2002) Expression of Pleurotus eryngii versatile peroxidase in Escherichia coli and optimisation of in vitro folding. Enzyme Microb. Technol., 30, 518-524

17 Ruiz-Dueñas, F. J., Martínez, M. J. and Martínez, A. T. (1999) Molecular characterization of a novel peroxidase isolated from the ligninolytic fungus Pleurotus eryngii. Mol. Microbiol., 31, 223-236

18 Britton, H. T. S. and Robinson, R. A. (1931) Universal buffer soluttons and the association constant of veronal. Journal of the Chemical Society, 1456-1462

19 Kabsch, W. (2010) XDS. Acta Crystallographica Section D-Biological Crystallography, 66, 125-132

20 Adams, P. D., Afonine, P. V., Bunkoczi, G., Chen, V. B., Davis, I. W., Echols, N., Headd, J. J., Hung, L. W., Kapral, G. J., Grosse-Kunstleve, R. W., Mccoy, A. J., Moriarty, N. W., Oeffner, R., Read, R. J., Richardson, D. C., Richardson, J. S., Terwilliger, T. C. and Zwart, P. H. (2010) PHENIX: a comprehensive Python-based system for macromolecular structure solution. Acta Crystallographica Section D-Biological Crystallography, 66, 213-221

21 Emsley, P., Lohkamp, B., Scott, W. G. and Cowtan, K. (2010) Features and development of Coot. Acta Crystallographica Section D-Biological Crystallography, 66, 486-501

22 Chen, V. B., Arendall, W. B., Headd, J. J., Keedy, D. A., Immormino, R. M., Kapral, G. J., Murray, L. W., Richardson, J. S. and Richardson, D. C. (2010) MolProbity: all-atom structure validation for macromolecular crystallography. Acta Crystallographica Section D-Biological Crystallography, 66, 12-21

23 Davis, I. W., Leaver-Fay, A., Chen, V. B., Block, J. N., Kapral, G. J., Wang, X., Murray, L. W., Arendall III, W. B., Snoeyink, J., Richardson, J. S. and Richardson, D. C. (2007) MolProbity: all-atom contacts and structure validation for proteins and nucleic acids. Nucleic Acids Res., 35, W375-W385

24 Sastry, G. M., Adzhigirey, M., Day, T., Annabhimoju, R. and Sherman, W. (2013) Protein and ligand preparation: parameters, protocols, and influence on virtual screening enrichments. Journal of Computer-Aided Molecular Design, 27, 221-234

25 Kaminski, G. A., Friesner, R. A., Tirado-Rives, J. and Jorgensen, W. L. (2001) Evaluation and reparametrization of the OPLS-AA force field for proteins via comparison with accurate quantum chemical calculations on peptides. J. Phys. Chem. B, 105, 6474-6487

26 Nosé, S. (1984) A unified formulation of the constant temperature molecular dynamics methods. J. Chem. Phys., 81, $511-519$

27 Martyna, G. J., Tobias, D. J. and Klein, M. L. (1994) Constant-Pressure Molecular-Dynamics Algorithms. J. Chem. Phys., 101, 4177-4189

28 Nie, G. J., Reading, N. S. and Aust, S. D. (1999) Relative stability of recombinant versus native peroxidases from Phanerochaete chrysosporium. Arch. Biochem. Biophys., 365, 328-334 
29 Olden, K., Bernard, B. A., Humphries, M. J., Yeo, T. K., Yeo, K. T., White, S. L., Newton, S. A., Bauer, H. C. and Parent, J. B. (1985) Function of Glycoprotein Glycans. Trends in Biochemical Sciences, 10, 78-82

30 Tams, J. W. and Welinder, K. G. (1998) Glycosylation and thermodynamic versus kinetic stability of horseradish peroxidase. FEBS Lett., 421, 234-236

31 George, S. J., Kvaratskhelia, M., Dilworth, M. J. and Thorneley, R. N. F. (1999) Reversible alkaline inactivation of lignin peroxidase involves the release of both the distal and proximal site calcium ions and bishistidine co-ordination of the haem. Biochem. J., 344, 237-244

32 Youngs, H. L., Moënne-Loccoz, P., Loehr, T. M. and Gold, M. H. (2000) Formation of a bis(histidyl) heme iron complex in manganese peroxidase at high $\mathrm{pH}$ and restoration of the native enzyme structure by calcium. Biochemistry, 39, 9994-10000

33 Verdín, J., Pogni, R., Baeza, A., Baratto, M. C., Basosi, R. and Vázquez-Duhalt, R. (2006) Mechanism of versatile peroxidase inactivation by Ca2+ depletion. Biophys. Chem., 121, 163-170

34 Pérez-Boada, M., Ruiz-Dueñas, F. J., Pogni, R., Basosi, R., Choinowski, T., Martínez, M. J., Piontek, K. and Martínez, A. T. (2005) Versatile peroxidase oxidation of high redox potential aromatic compounds: Site-directed mutagenesis, spectroscopic and crystallographic investigations of three long-range electron transfer pathways. J. Mol. Biol., 354, 385-402

35 Santoni, E., Jakopitsch, C., Obinger, C. and Smulevich, G. (2004) Comparison between catalase-peroxidase and cytochrome $\mathrm{c}$ peroxidase. The role of the hydrogen-bond networks for protein stability and catalysis. Biochemistry USA, 43, 5792-5802

36 Henriksen, A., Mirza, O., Indiani, C., Teilum, K., Smulevich, G., Welinder, K. G. and Gajhede, M. (2001) Structure of soybean seed coat peroxidase: A plant peroxidase with unusual stability and haem-apoprotein interactions. Protein Sci., 10, 108-115

37 Mirza, O., Henriksen, A., Ostergaard, L., Welinder, K. G. and Gajhede, M. (2000) Arabidopsis thaliana peroxidase $\mathrm{N}$ : structure of a novel neutral peroxidase. Acta Crystallographica Section D-Biological Crystallography, 56, 372-375

38 Kamal, J. K. A. and Behere, D. V. (2008) Kinetic stabilities of soybean and horseradish peroxidases. Biochem. Eng. J., 38, 110-114

39 Vogt, G., Woell, S. and Argos, P. (1997) Protein thermal stability, hydrogen bonds, and ion pairs. J. Mol. Biol., 269, $631-643$

40 Kumar, S., Tsai, C. J. and Nussinov, R. (2000) Factors enhancing protein thermostability. Protein Eng., 13, 179-191

41 Vinther, J. M., Kristensen, S. M. and Led, J. J. (2011) Enhanced Stability of a Protein with Increasing Temperature. J. Am. Chem. Soc., 133, 271-278

42 Gromiha, M. M., Pathak, M. C., Saraboji, K., Ortlund, E. A. and Gaucher, E. A. (2013) Hydrophobic environment is a key factor for the stability of thermophilic proteins. Proteins, 81, 715-721

43 Hiner, A. N. P., Raven, E. L., Thorneley, R. N. F., García-Canovas, F. and Rodríguez-López, J. N. (2002) Mechanisms of compound I formation in heme peroxidases. J. Inorg. Biochem., 91, 27-34

44 Erman, J. E., Vitello, L. B., Miller, M. A., Shaw, A., Brown, K. A. and Kraut, J. (1993) Histidine 52 is a critical residue for rapid formation of cytochrome $c$ peroxidase compound I. Biochemistry, 32, 9798-9806

45 Vitello, L. B., Erman, J. E., Miller, M. A., Wang, J. and Kraut, J. (1993) Effect of Arginine-48 replacement on the reaction between cytochrome $c$ peroxidase and hydrogen peroxide. Biochemistry, 32, 9807-9818

46 Ruiz-Dueñas, F. J., Morales, M., Pérez-Boada, M., Choinowski, T., Martínez, M. J., Piontek, K. and Martínez, A. T. (2007) Manganese oxidation site in Pleurotus eryngii versatile peroxidase: A site-directed mutagenesis, kinetic and crystallographic study. Biochemistry, 46, 66-77

47 Banci, L., Camarero, S., Martínez, A. T., Martínez, M. J., Pérez-Boada, M., Pierattelli, R. and Ruiz-Dueñas, F. J. (2003) NMR study of Mn(II) binding by the new versatile peroxidase from the white-rot fungus Pleurotus eryngii. J. Biol. Inorg. Chem., 8, 751-760

48 Banci, L., Bertini, I., Turano, P., Tien, M. and Kirk, T. K. (1991) Proton NMR investigation into the basis for the relatively high redox potential of lignin peroxidase. Proc. Natl. Acad. Sci. USA, 88, 6956-6960 
Table 1

Seven mutations present in 2-1B and their combination in the five intermediate variants analyzed in this study

\begin{tabular}{llll}
\hline Variants & Mutations & & \\
\hline $2-1 B$ & E37K / H39R / V160A / T184M / Q202L / D213A / G330R \\
H39R & $\quad$ H39R & \\
EG & E37K / & G330R \\
EHG & E37K / H39R / & G330R \\
EHGQ & E37K / H39R / & Q202L / & G330R \\
EHGT & E37K / H39R / & T184M / & G330R \\
\hline
\end{tabular}

Table 2

Kinetic constants $-K_{m}(\mu \mathrm{M}), k_{\text {cat }}\left(s^{-1}\right)$ and $k_{\text {cat }} / K_{m}\left(s^{-1} \mathrm{mM}^{-1}\right)$ - for oxidation of VA, RB5, Mn ${ }^{2+}$, ABTS and DMP by native VP, 2-1B and three intermediate variants (see Table 1 for mutations in each of them) ${ }^{a}$

\begin{tabular}{|c|c|c|c|c|c|c|}
\hline & & VP & EHG & $E H G Q$ & EHGT & $2-1 B$ \\
\hline \multirow{3}{*}{ VA } & $K_{m}$ & $2600 \pm 190$ & $2110 \pm 150$ & $1780 \pm 60$ & $5910 \pm 190$ & $2710 \pm 270$ \\
\hline & $k_{\text {cat }}$ & $5.8 \pm 0.1$ & $5.2 \pm 0.1$ & $4.4 \pm 0.04$ & $5.9 \pm 0.1$ & $3.8 \pm 0.1$ \\
\hline & $k_{\text {cat }} / K_{m}$ & $2.2 \pm 0.1$ & $2.5 \pm 0.1$ & $2.5 \pm 0.1$ & $1.0 \pm 0.1$ & $1.4 \pm 0.1$ \\
\hline \multirow{3}{*}{ RB5 } & $K_{m}$ & $3.4 \pm 0.3$ & $4.3 \pm 0.5$ & $3.5 \pm 0.3$ & $2.4 \pm 0.1$ & $7.6 \pm 0.6$ \\
\hline & $k_{\text {cat }}$ & $5.5 \pm 0.3$ & $7.8 \pm 0.4$ & $6.7 \pm 0.3$ & $5.1 \pm 0.1$ & $6.7 \pm 0.3$ \\
\hline & $k_{\text {cat }} / K_{m}$ & $1.6 \pm 0.1$ & $1.8 \pm 0.1$ & $1.1 \pm 0.1$ & $2.2 \pm 0.1$ & $0.8 \pm 0.1$ \\
\hline \multirow{3}{*}{$\begin{array}{l}\text { ABTS (high } \\
\text { efficiency) }\end{array}$} & $K_{m}$ & $3.0 \pm 0.2$ & $2.6 \pm 0.2$ & $2.3 \pm 0.2$ & $13 \pm 3$ & $\mathrm{nd}^{b}$ \\
\hline & $k_{\text {cat }}$ & $8.1 \pm 0.2$ & $8.3 \pm 0.3$ & $7.2 \pm 0.3$ & $39 \pm 7$ & $\mathrm{nd} \mathrm{d}^{b}$ \\
\hline & $k_{\text {cat }} / K_{m}$ & $2700 \pm 140$ & $3100 \pm 180$ & $3200 \pm 150$ & $3050 \pm 160$ & $n d^{b}$ \\
\hline \multirow{3}{*}{$\begin{array}{l}\text { ABTS (low } \\
\text { efficiency) }\end{array}$} & $K_{m}$ & $1020 \pm 70$ & $400 \pm 40$ & $280 \pm 20$ & $61 \pm 3$ & $98 \pm 9$ \\
\hline & $k_{\text {cat }}$ & $208 \pm 6$ & $89 \pm 2$ & $90 \pm 2$ & $117 \pm 2$ & $234 \pm 8$ \\
\hline & $k_{\text {cat }} / K_{m}$ & $204 \pm 10$ & $219 \pm 15$ & $320 \pm 20$ & $1920 \pm 70$ & $2370 \pm 150$ \\
\hline \multirow{3}{*}{$\begin{array}{l}\text { DMP (high } \\
\text { efficiency) }\end{array}$} & $K_{m}$ & $38 \pm 4$ & $17 \pm 2$ & $16 \pm 3$ & $11 \pm 2$ & $27 \pm 7$ \\
\hline & $k_{\text {cat }}$ & $7.1 \pm 0.1$ & $2.9 \pm 0.1$ & $4.1 \pm 0.1$ & $6.3 \pm 0.3$ & $2.9 \pm 0.4$ \\
\hline & $k_{\text {cat }} / K_{m}$ & $186 \pm 16$ & $168 \pm 18$ & $250 \pm 38$ & $559 \pm 80$ & $112 \pm 18$ \\
\hline \multirow{3}{*}{$\begin{array}{l}\text { DMP (low } \\
\text { efficiency) }\end{array}$} & $K_{m}$ & $10500 \pm 400$ & $34500 \pm 6050$ & $34100 \pm 5290$ & $3070 \pm 420$ & $7470 \pm 380$ \\
\hline & $k_{\text {cat }}$ & $30 \pm 1$ & $40 \pm 4$ & $56 \pm 4$ & $46 \pm 2$ & $91 \pm 2$ \\
\hline & $k_{\text {cat }} / K_{m}$ & $2.8 \pm 0.1$ & $1.1 \pm 0.1$ & $1.6 \pm 0.1$ & $15 \pm 2$ & $12 \pm 1$ \\
\hline \multirow{3}{*}{$\mathrm{Mn}^{2+}$} & $K_{m}$ & $130 \pm 11$ & $7020 \pm 190$ & $6790 \pm 200$ & $5590 \pm 371$ & $5710 \pm 350$ \\
\hline & $k_{\text {cat }}$ & $211 \pm 4$ & $208 \pm 2$ & $188 \pm 2$ & $160 \pm 4$ & $143 \pm 3$ \\
\hline & $k_{\text {cat }} / K_{m}$ & $1640 \pm 130$ & $30 \pm 1$ & $28 \pm 1$ & $29 \pm 1$ & $25 \pm 1$ \\
\hline
\end{tabular}

a Reactions were carried out at $25^{\circ} \mathrm{C}$ in $0.1 \mathrm{M}$ sodium tartrate ( $\mathrm{pH} 3$ for VA, $\mathrm{pH} 5$ for $\mathrm{Mn}^{2+}$, and $\mathrm{pH} 3.5$ for RB5, ABTS and DMP). Means and $95 \%$ confidence limits of replicate assays. ABTS and DMP oxidation showed biphasic kinetics enabling calculation of two sets of constants (for high and low efficiency sites). ${ }^{b}$ Not determined because the kinetic curve of the high efficiency site overlapped with that of the low efficiency site. 


\section{Figure $1 \mathrm{pH}$ stability of native VP and three mutated variants}

Residual activities of VP (A) and the EHG (B) EHGQ (C) and 2-1B (D) variants, after $1 \mathrm{~h}$ (gray bars), $4 \mathrm{~h}$ (white bars), $24 \mathrm{~h}$ (black bars), and $120 \mathrm{~h}$ (striped bars) of incubation in $0.1 \mathrm{M} \mathrm{B \& R}$ buffer at different $\mathrm{pH}$ values (3-9) and $4^{\circ} \mathrm{C}$. Residual activity measured as ABTS (2 mM) oxidation in $0.1 \mathrm{M}$ sodium tartrate (pH 3.5) using $0.01 \mu \mathrm{M}$ enzyme and $0.1 \mathrm{mM} \mathrm{H}_{2} \mathrm{O}_{2}$. Means and $95 \%$ confidence limits of replicate assays. See Table 1 for the mutations present in each of the variants.

\section{Figure 2 Electronic absorption spectra of native VP and variants after treatments at $\mathrm{pH} \mathbf{5}$ and $\mathrm{pH} \mathbf{8}$}

UV-visible spectra of native VP (A) and the EHG (B), EHGQ (C) and 2-1B (D) variants incubated for $120 \mathrm{~h}$ in $0.1 \mathrm{M} \mathrm{B} \& \mathrm{R}$ buffer at $\mathrm{pH} 5$ (black) and pH 8 (gray), at $4^{\circ} \mathrm{C}$. Amplified $(\times 5)$ 450-800 nm regions are shown. Main maxima are indicated.

\section{Figure 3 E37K and H39R mutations in 2-1B and EHG crystal structures}

Crystal structure of $2-1 B(A)$ with details of the region in front of the heme propionates in native VP $(B)$ and the EHG (C) and 2-1B (D) variants showing the heme, the mutated residues at positions 37 and 39, and other surrounding residues (in CPK colours). Hydrogen bonds are shown as green dashed lines, calcium ions as green spheres and secondary structure as colour cartoon.

\section{Figure 4 Q202L mutation in 2-1B crystal structure}

Crystal structure of 2-1B (A) with a detail of the region around residue 202 in native VP (B) and the 2-1B (C) variant. Analyzed residues are shown as CPK sticks, hydrogen bonds as green dashed lines, calcium ions as green spheres and secondary structure as coloured cartoon.

\section{Figure 5 Molecular dynamics simulations.}

Distance profiles between the heme iron and the distal His-47 (A) and between the distal His-47 and Arg-43 (B); and representative snapshots, with the average distances, extracted from the MD simulations of 2-1B (C) and native VP (D). All distances are in Angstroms. 
FIGURE 1 (2 columns)
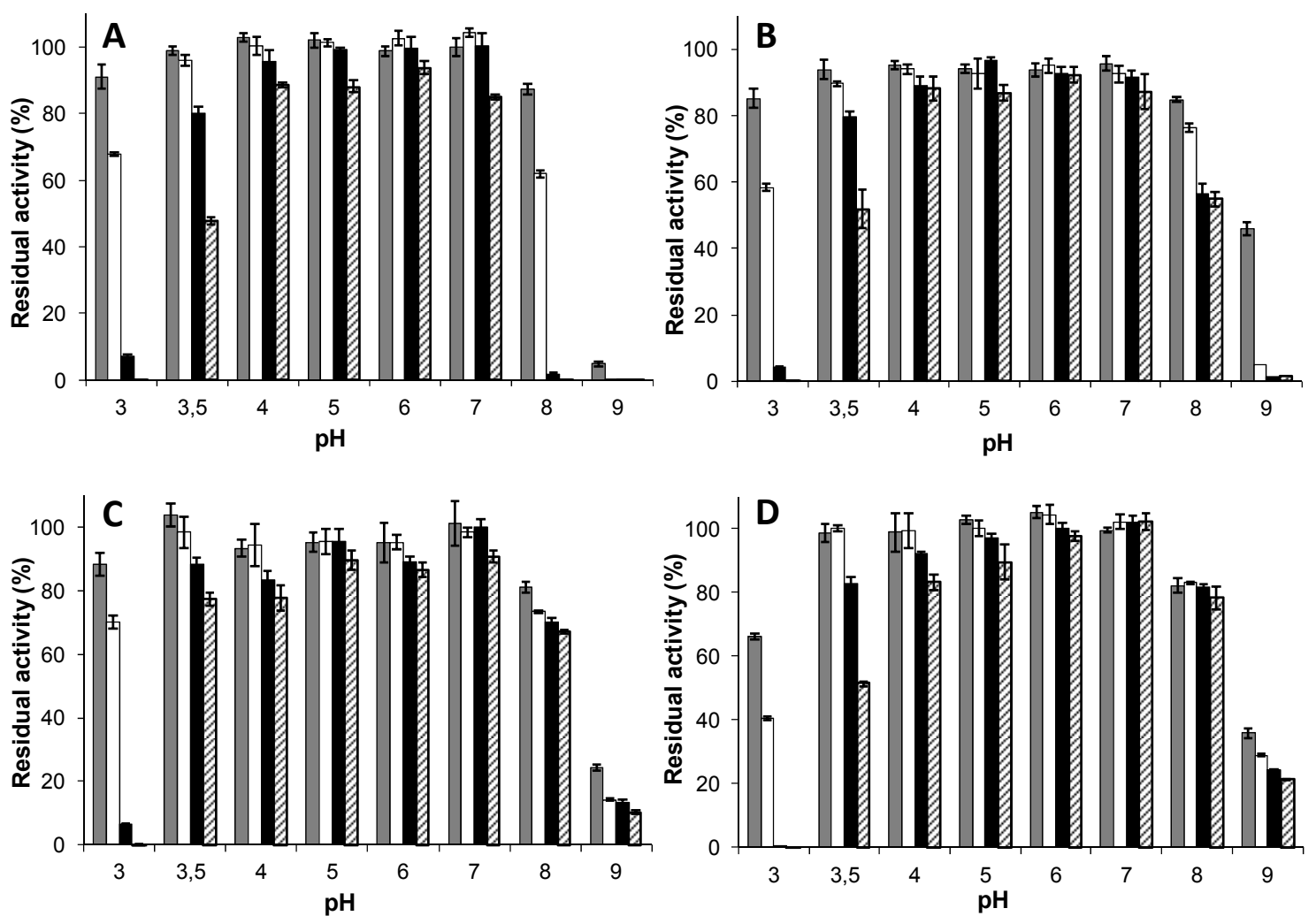
FIGURE 2 (2 columns)
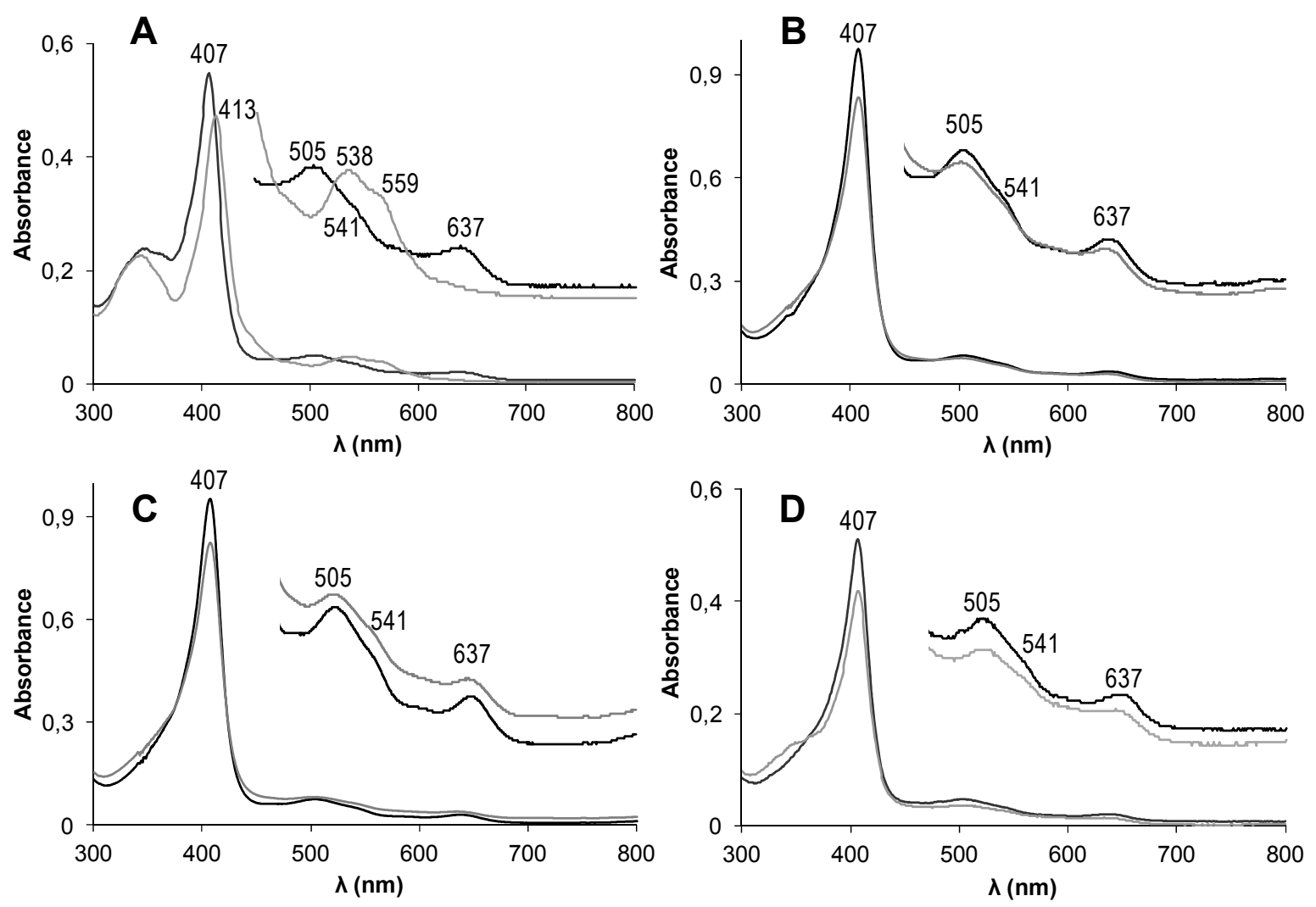
FIGURE 3 (2 columns)
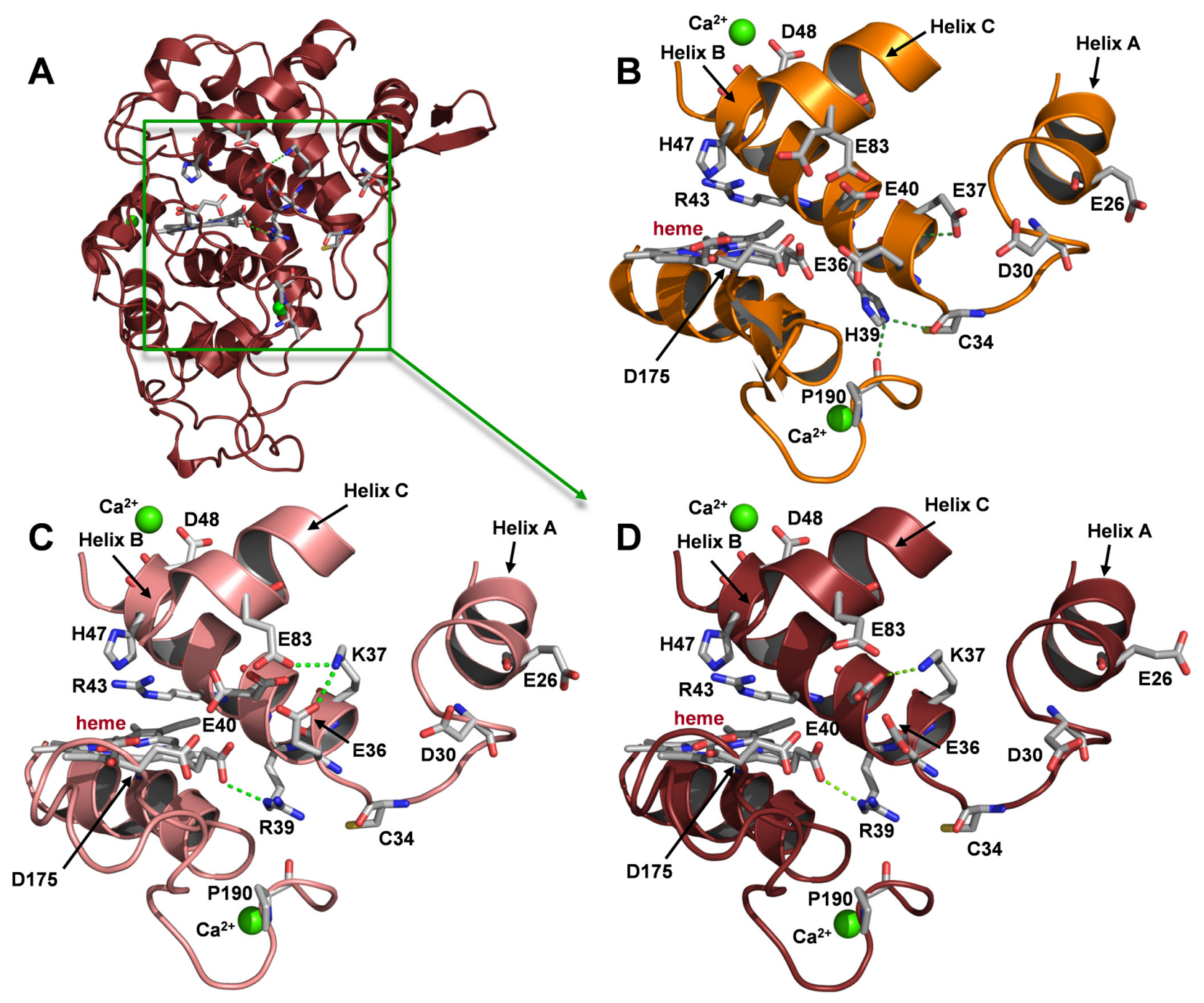
FIGURE 4 (2 columns)

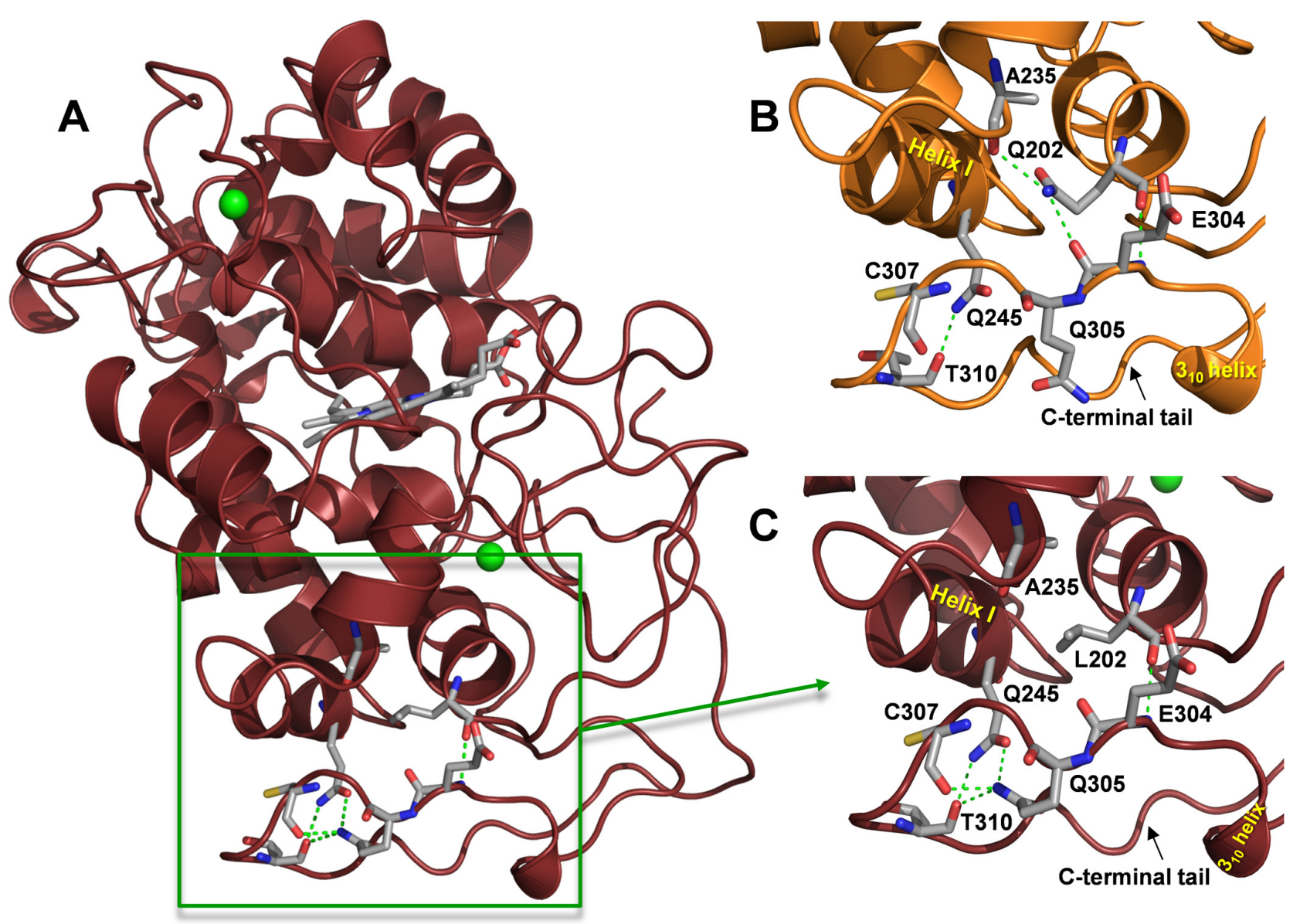


FIGURE 5 (2 columns)
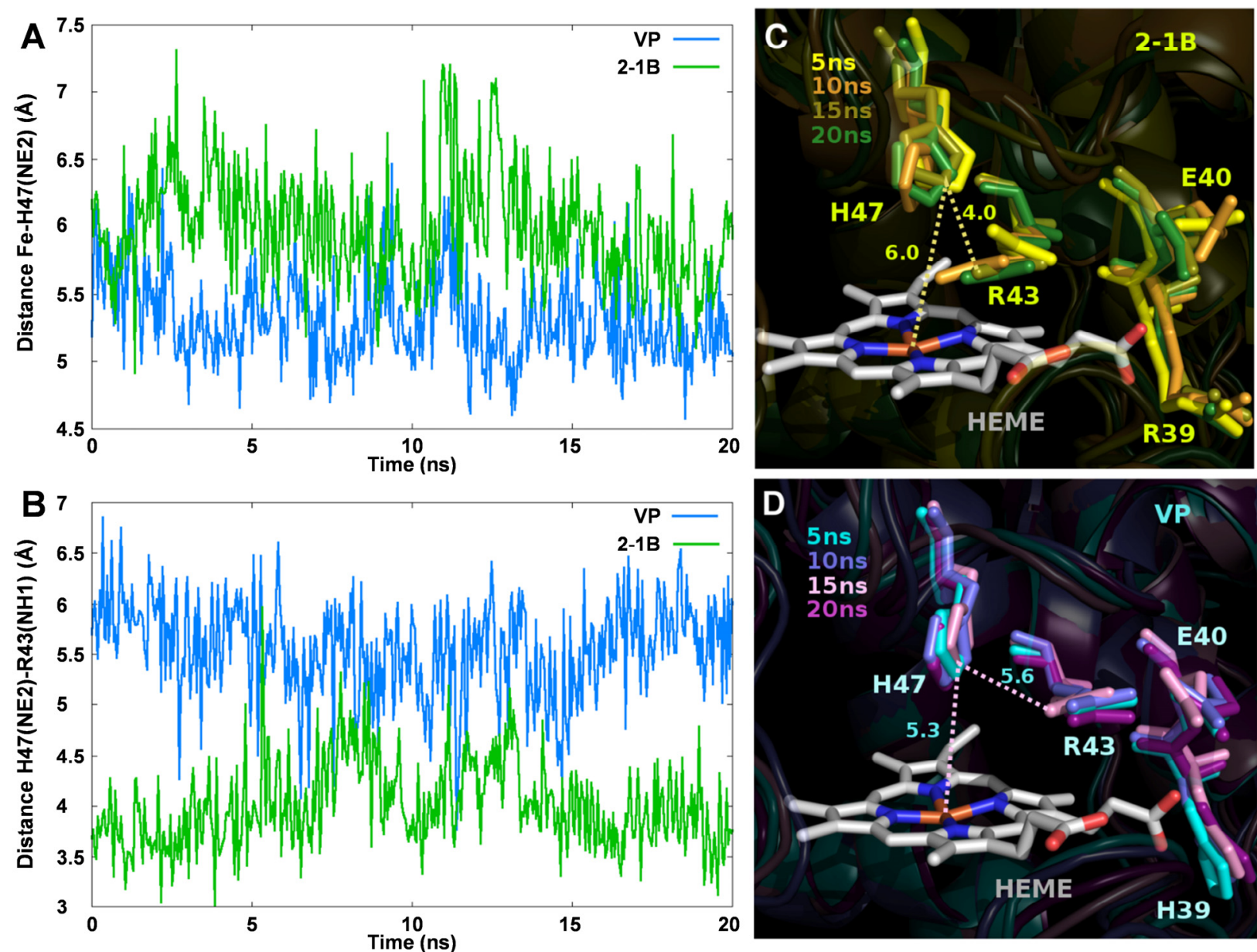


\title{
SUPPLEMENTARY ONLINE DATA
}

\section{Unveiling the bases of alkaline stability of an evolved versatile peroxidase}

\author{
Verónica SÁEZ-JIMÉNEZ*, Sandra ACEBES ††, Eva GARCIA-RUIZ§, Antonio ROMERO*, Victor \\ GUALLAR $\dagger \|$, Miguel ALCALDE\#, Francisco J. MEDRANO*, Angel T. MARTÍNEZ* and Francisco J. RUIZ- \\ DUEÑAS*
}

*Centro de Investigaciones Biológicas, CSIC, Ramiro de Maeztu 9, E-28040 Madrid, Spain

†Joint BSC-CRG-IRB Research Program in Computational Biology, Barcelona Supercomputing Center, Jordi Girona 29, E-08034 Barcelona, Spain

$\$$ Anaxomics Biotech, Balmes 89, E-08008 Barcelona, Spain

$\S$ Department of Chemical and Biomolecular Engineering, University of Illinois at Urbana-Champaign, 600 South Mathews Avenue, Urbana, Illinois 61801, USA

॥ICREA, Passeig Lluis Companys 23, E-08010 Barcelona, Spain

\#Institute of Catalysis and Petroleochemistry, CSIC, Marie Curie 2, Cantoblanco, E-28049 Madrid, Spain

\section{SUPPLEMENTARY TABLES AND FIGURE}

Table S1 Oligonucleotide primers used in mutagenic PCRs for the production of the VP variants Only the direct sequences are shown with indication of the changed triplets (underlined) and the mutations introduced (bold).

\begin{tabular}{lll}
\hline Primer & Sequence 5'-3' & Mutation \\
\hline E37K $_{p}$ & GCCCAGTGTGGAGAAAAGGTGCACGAGTCCC & E37K \\
H39R $_{p}$ & GGAGAAGAGGTGCGCGAGTCCCTTCGTTTGACTTTCCACG & H39R \\
G330R $_{p}$ & CCCTCCCGTCCCTAGATCGTAAGATCTCTCG & G330R \\
Q202L & CTCAATTCTTCATCGAAACGCTCCTTAAAGGCAGACTCTTCCCC & Q202L \\
T184M $_{p}$ & CCCATCCGATTCCTGGAATGCATTCGATTCAACCCCCGG & T184M \\
E37K/H39R & GCCCAGTGTGGAGAAAAGGTGCGCGAGTCCCTTCG & E37K/H39R \\
\hline
\end{tabular}


Table S2 Crystallographic data collection and refinement statistics of VP EHG and VP 2-1B. Data in parenthesis correspond to the last resolution layer.

\begin{tabular}{|c|c|c|}
\hline Data collection & EHG & $2-1 \mathrm{~B}$ \\
\hline Space group & $P 2,2,2$ & $P 2,2,2$ \\
\hline Cell constants & $a=55.2, b=104.2, c=76.6 \AA$ & $a=55.1, b=106.0, c=107.6 \AA$ \\
\hline Resolution range $(\AA ̊)$ & $50.00-1.50(1.59-1.50)$ & $50.00-1.80(1.90-1.80)$ \\
\hline $\mathrm{N}^{0}$ of total reflections & 920257 & 777990 \\
\hline $\mathrm{N}^{0}$ of unique reflections & 71617 & 59335 \\
\hline $\mathrm{R}_{\text {merge }}(\%)$ & $26.6(324.2)$ & $41.2(330.8)$ \\
\hline Completeness (\%) & $99.5(97.2)$ & $98.6(94.2)$ \\
\hline$<|/ s(\mid)\rangle$ & $8.5(0.8)$ & $6.8(0.7)$ \\
\hline Multiplicity & $12.8(12.0)$ & $13.1(12.0)$ \\
\hline $\operatorname{CC}(1 / 2)$ & $99.7(28.8)$ & $99.0(30.9)$ \\
\hline Solvent content (\%) / Matthews coef. & $55.33 / 2.75$ & $37.48 / 1.97$ \\
\hline Subunits per asymmetric unit & 1 & 2 \\
\hline Wilson $B$ factor $\left(\AA^{2}\right)$ & 16.0 & 26.8 \\
\hline \multicolumn{3}{|l|}{ Refinement } \\
\hline Resolution range & $50.0-1.50 \AA$ & $50.0-1.80 \AA$ \\
\hline Working reflections & 71227 & 58796 \\
\hline$R_{\text {work }} / R_{\text {free }}$ & 19.2 / $22.9 \%$ & $18.5 / 21.9 \%$ \\
\hline Protein atoms $($ non $\mathrm{H})$ & 2440 & 4740 \\
\hline Heme group & 1 & 2 \\
\hline $\mathrm{Ca}^{2+}$ & 2 & 4 \\
\hline Water molecules & 367 & 618 \\
\hline $\mathrm{SO}_{4}$ ions & 10 & 2 \\
\hline \multicolumn{3}{|l|}{ Mean B factors $\left(\AA^{2}\right)$} \\
\hline Protein atoms (non $\mathrm{H})$ & 20.07 & 21.41 \\
\hline Heme group & 15.37 & 17.85 \\
\hline $\mathrm{Ca}^{2+}$ & 14.63 & 15.57 \\
\hline Water molecules & 30.98 & 38.23 \\
\hline $\mathrm{SO}_{4}$ ions & 62.93 & 30.51 \\
\hline \multicolumn{3}{|l|}{ Deviations from ideality } \\
\hline rmsd bond lengths & $0.006 \AA$ & $0.007 \AA$ \\
\hline rmsd angles & $1.126^{\circ}$ & $1.104^{\circ}$ \\
\hline \multicolumn{3}{|l|}{ Ramachandran plot statistics } \\
\hline Preferred \% & 98.47 & 98.43 \\
\hline Allowed \% & 1.53 & 1.57 \\
\hline Outliers \% & 0.00 & 0.00 \\
\hline PDB code & 5 fne & $5 \mathrm{fnb}$ \\
\hline
\end{tabular}



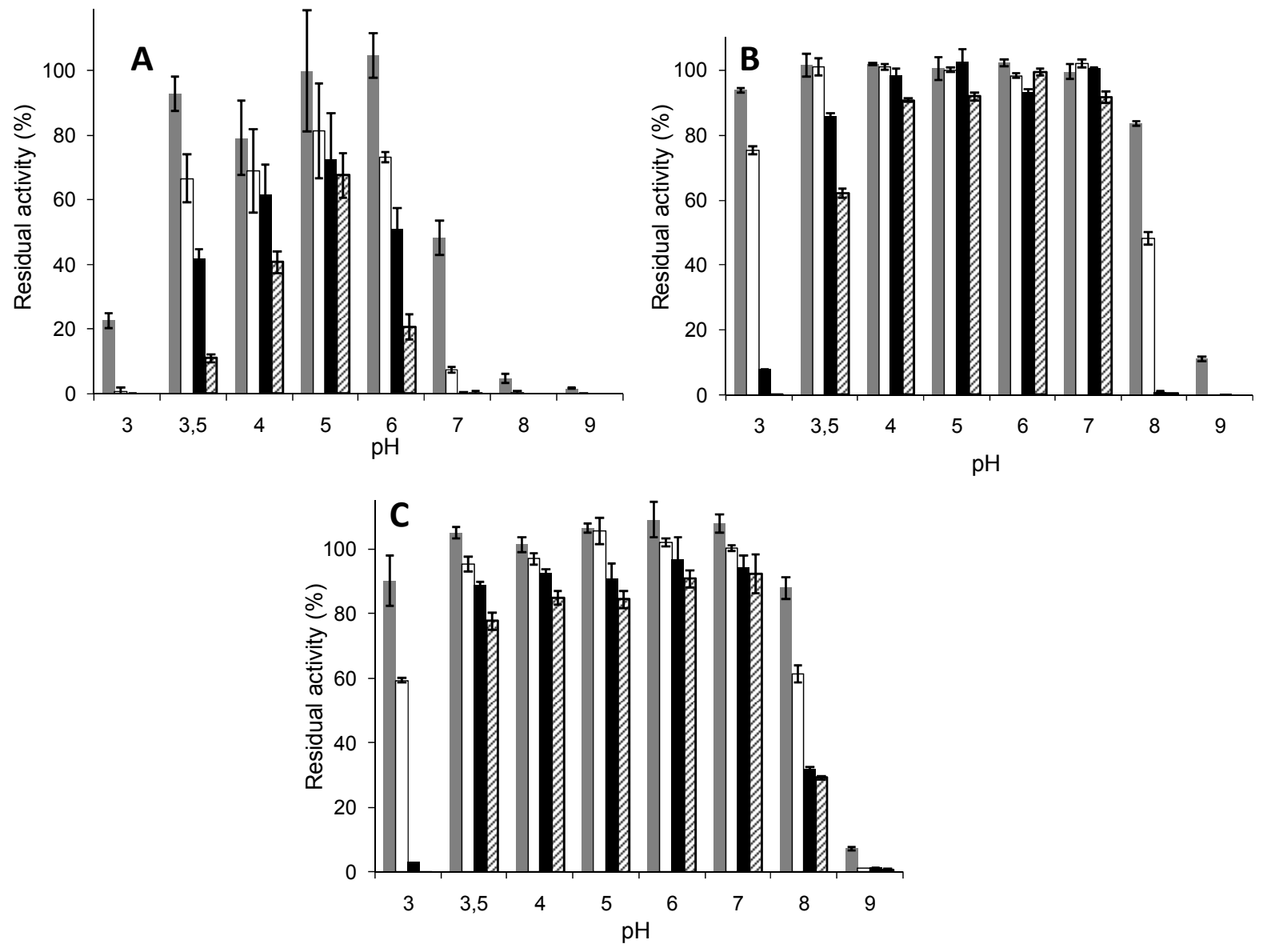

Figure S1 pH stability of H39R, EG (E37K/G330R) and EHGT (E37K/H39R/G330R/T184M) VP variants

Residual activities of H39R (A), EG (B) and EHGT (C) after incubation in $0.1 \mathrm{M}$ Britton \& Robinson buffer at different $\mathrm{pH}$ values (3-9) and $4^{\circ} \mathrm{C}$ for $1 \mathrm{~h}$ (gray bars), $4 \mathrm{~h}$ (white bars), $24 \mathrm{~h}$ (black bars), and $120 \mathrm{~h}$ (striped bars). Residual activity measured as ABTS $(2 \mathrm{mM})$ oxidation in $0.1 \mathrm{M}$ sodium tartrate (pH 3.5) using $0.01 \mu \mathrm{M}$ enzyme and $0.1 \mathrm{mM} \mathrm{H}_{2} \mathrm{O}_{2}$. Means and $95 \%$ confidence limits of replicate assays. 